\title{
A GESTÃO DE PESSOAS COMO DIFERENCIAL EM ESCOLAS DE ENSINO TÉCNICO PROFISSIONALIZANTES: UM CONSTRUCTO TEÓRICO
}

\author{
Mauro Rodrigo de Almeida Freitas ${ }^{1}$ \\ Francisco Nilton Gomes de Oliveira ${ }^{2}$
}

RESUMO: Este artigo é decorrente da dissertação de mestrado: "A Gestão de Pessoas como diferencial em escolas técnico profissionalizante: um constructo teórico". Dessa forma, esse artigo se caracteriza por ser um retrato da dissertação em questão e que um dos objetivos consiste na elaboração de dois artigos acadêmicos, tecendo a gestão de pessoas versus Educação Profissional e Tecnológica (EPT). Também se destaca em discorrer por meio da literatura as correntes epistemológicas em Gestão de pessoas e Educação Profissional e Tecnológica no Brasil, utilizando como aspectos metodológicos, uma revisão bibliográfica sobre a vertente gestão de pessoas versus educação profissional e tecnológica. Os resultados apontaram dois artigos com a seguinte temática: Gestão de pessoas como diferencial competitivo nas instituições de ensino técnico profissionalizantes do município de Santa Maria, RS, e A gestão de pessoas como diferencial em escolas de ensino técnico profissionalizante: um constructo teórico.

Palavras-Chave: Gestão de pessoas. Instituições de ensino técnico profissionalizante. Diferencial competitivo.

ABSTRACT: This article derives from the master's thesis: "People Management as a differential in vocational technical schools: a theoretical construct". Thus, this article is characterized by being a portrait of the dissertation in question and that one of the objectives is the elaboration of two academic articles, weaving people management versus Professional and Technological Education (EPT). It also stands out in discussing through the literature the epistemological currents in People Management and Professional and Technological Education in Brazil, using as methodological aspects, a literature review on the aspect of people management versus professional and technological education. The results pointed to two articles with the following theme: People management as a competitive differential in vocational technical education institutions in the city of Santa Maria, RS, and People management as a differential in vocational technical education schools: a theoretical construct.

${ }^{\mathrm{I}}$ Mestrando do Curso de Mestrado Acadêmico em Educação Profissional e Tecnológica - PPGPETUFSM.

${ }^{2}$ Doutorado pela UFPE. Orientador.Emeil; niltonufrj@gmail.com. 
Keywords: People management. Vocational technical education institutions. competitive edge.

\section{INTRODUÇÃO}

Este artigo é oriundo de uma dissertação de mestrado intitulada: "A Gestão de Pessoas como diferencial em escolas técnico profissionalizante: um constructo teórico" do Programa de Pós-Graduação em Educação Profissional e Tecnológica (PPGEPT/UFSM). Através do estudo buscou discorrer por meio da literatura as correntes epistemológicas entre a vertente Gestão de pessoas versus Educação Profissional e Tecnológica no Brasil.

Dada a importância da gestão de pessoas para um processo de entrega de um serviço/produto de qualidade por parte das instituições de ensino técnico profissionalizante, e a minha necessidade de se saber se o que estava realmente sendo realizado referente a estas questões nas instituições de ensino, fez com que no primeiro momento eu procurasse algumas intuições para que buscasse essas informações. Devido ao momento de pandemia que estamos passando não foi possível fazer uma busca in loco. E ao deflagrar uma certa escassez de material referente a esta vertente, em comum acordo com o orientador, foi definido um percurso metodológico que compreendeu em fazer uma revisão de literatura narrativa sobre a vertente gestão de pessoas versus educação profissional e tecnológica e a elaboração de 2 artigos científicos com intuído de publicação, incluindo o mesmo.

Este tema de dissertação surge dada a importância da gestão de pessoas para um processo de entrega de um serviço/produto de qualidade por parte das instituições de ensino técnico profissionalizante, e a necessidade do pesquisador de se saber se o que estava realmente sendo realizado referente a ao que era ofertado nas instituições de ensino técnico profissionalizantes.

Partindo do princípio que as instituições de ensino técnico profissionalizantes, "entregam" os serviços/produtos que se é ofertado, a impossibilidade de uma pesquisa in loco em momento de pandemia, constitui-se 
como objetivo geral da pesquisa a elaboração de dois artigos científicos tecendo a vertente Gestão de pessoas versus educação profissional e tecnológica.

Nesse sentido, este artigo se caracteriza por ser um recorte da dissertação de mestrado em que um dos objetivos consiste em discorrer por meio da literatura as correntes epistemológicas em gestão de pessoas e Educação Profissional e Tecnológica no Brasil. Por fim resultou-se na produção dos artigos intitulados respectivamente: Gestão de pessoas como diferencial competitivo nas instituições de ensino técnico profissionalizantes do município de Santa Maria, RS, e A gestão de pessoas como diferencial em escolas de ensino técnico profissionalizante: um constructo teórico.

\section{METODOLOGIA}

Essa pesquisa caracterizou com uma pesquisa bibliográfica. Segundo Gil (2006), a pesquisa bibliográfica possibilita ao leitor visões teóricas sobre determinadas temáticas ou assuntos. Trata-se de uma pesquisa bibliográfica. Para o autor (2006), a Pesquisa bibliográfica é o passo inicial na construção efetiva de um protocolo de investigação, quer dizer, após a escolha de um assunto é necessário fazer uma revisão bibliográfica do tema apontado. Essa pesquisa auxilia na escolha de um método mais apropriado, assim como num conhecimento das variáveis e na autenticidade da pesquisa.

\section{RESULTADOS E DISCUSSÃO}

Este artigo buscou apresentar os conceitos de Gestão de Pessoas, por meio da literatura e transcrição dos conceitos referenciados na dissertação, discorrendo por meio de conceitos voltados para a importância da gestão de pessoas, no processo de gestão dentro de uma instituição escolar.

Destacou também que uma gestão de pessoas adequada incorporada como um elemento estratégico nas organizações, faz com que as ações implementadas tenham como objetivo principal resultados positivos de desenvolvimento pessoal e profissional dos envolvidos. 
Descreveu a possibilidade inicial de se pesquisar o processo de entrega de um serviço/produto de qualidade por parte das instituições de ensino técnico profissionalizante, e seus "efeitos" junto aos sujeitos envolvidos, na qual seriam os docentes e discentes nas instituições.

Nesta concepção de entender a responsabilidade exercida por parte da gestão de pessoas nas instituições, buscou-se no primeiro momento bases literárias referentes a temática em estudo, posteriormente uma pesquisa in loco nas instituições. Durante o percurso da dissertação, diante das dificuldades de se obter uma esta pesquisa in loco, devido a não estarem "abertas" para esta pesquisa, o foco passou a ser de uma busca exclusivamente literária e bibliográfica, no que tange educação profissional e os desafios de gestão de pessoas junto as estas organizações

Uma análise dos fatores que envolvem o trabalho do gestor de pessoas, aliando-os aos pressupostos da Educação Profissional e tecnológica, procurou-se abortar na dissertação. Aspectos relevantes no que se refere e historicidade tanto da gestão de pessoas, quanto da educação profissional e tecnológica, de certa forma foram abortados na dissertação. O foco inicial em uma educação voltada para formação de sujeitos (aluno), com intuito de servir os mais ricos em uma certa época, e também a formação de aluno para uma prestação adequada junto a comunidade externa.

\section{CONSIDERAÇÕES FINAIS}

Procurou-se, neste artigo, então descrever de uma forma simples os aspectos abordados na dissertação em questão, conceitos de gestão de pessoas, sua relevância, fatores importantes na formação e qualificação dos atores envolvidos em uma instituição de ensino técnico profissionalizante, para que entregam um serviço/produto de qualidade para os alunos que a procuram.

\section{REFERÊNCIAS}

ARAUJO, L. C. G. Gestão de pessoas: estratégias e integração organizacional. São Paulo: Atlas, 2006. 
AVILA, L. V.; STECCA, JP. Gestão de pessoas. Santa Maria: Universidade Federal de Santa Maria, Colégio Politécnico; Rede e-Tec Brasil, 2015.

BITENCOURT, C. Gestão contemporânea de pessoas: novas práticas, conceitos tradicionais. 2. ed. Porto Alegre: Bookman, 2010.

BOOG, G. G. Manual de treinamento e desenvolvimento. ABTD. 3. ed. São Paulo: Makron Books, 1999.

BOOG, G. G.; BOOG, M. Manual de treinamento e desenvolvimento: processos e operações. 6. ed. São Paulo: Pearson Education do Brasil, 2013.

BOHLANDER, G; SNELL, S; SHERMAN, A. Administração de recursos humanos. São Paulo: Pioneira Thomson Learning, 2005.

CARVAlHO, A. V. de; NASCIMENTO, L. P. do. Administração de recursos humanos. 2. ed. São Paulo: Pioneira, 1997.

CHIAVENATO, I. Administração de recursos humanos. 2. ed. São Paulo: Atlas, I98I.

Introdução à teoria geral da administração. 5. ed. Rio de Janeiro: Campus, I999.

Gestão de pessoas: e o novo papel dos recursos humanos nas organizações. 2. ed. Rio de Janeiro: Elsevier, 2004.

Gestão de pessoas: e o novo papel dos recursos humanos nas organizações. 3. ed. Rio de Janeiro: Elsevier, 2010.

CORDEIRO, Alexander Magno; OLIVEIRA, Glória Maria de; RENTERÍA, Juan Miguel; GUIMARÃES, Carlos Alberto. Revisão Sistemática: Uma Revisão narrativa. Revista Colégio Brasileiro de Cirurgióes, Rio de Janeiro - RJ, v. 34, n. 6, p.428-431, nov. 2007. Disponível em: <https://www.scielo.br/j/rcbc/a/CC6NRNtP3 3 KLgLPwcgmV6Gf/?format=pdf\&1 ang=pt $>$, Acesso em 23 outubro 2021.

DESSLER, G. Administração de recursos humanos. São Paulo: Prentice Hall, 2003.

DUTRA, J. S. Gestão de pessoas: modelo, processos, tendências e perspectivas. São Paulo: Atlas, 2009.

FRANÇA, A. C. L. Práticas de recursos humanos PRH: conceitos, ferramentas e procedimentos. São Paulo: Atlas, 2010.

GIL, A. C. Gestão de pessoas. São Paulo: Atlas, 2007. 
Métodos e técnicas de pesquisa social. 5. ed. São Paulo: Atlas, 2006.

LACOMBE, F. J. M. Recursos humanos: princípios e tendências. São Paulo: Saraiva, 2005 .

MARRAS, Jean Pierre. Administração de recursos humanos: Do operacional ao estratégico. 3. ed. São Paulo: Futura, 2000.

Administração de recursos humanos. 3. ed. São Paulo: Futura, 2002.

MASCARENHAS, A. O. Gestão estratégica de pessoas. São Paulo: Cengage Learning, 2008.

MATTAR, F. N,. Pesquisa de marketing, metodologia, planejamento. 3. ed. São Paulo: Atlas, 1996.

MEISTER, J. C. Educação corporativa. São Paulo: Makron Books, I999.

MILKOVICH, G. T.; BOUDREAU, J. W. Administração de recursos humanos. São Paulo: Atlas, 2008.

MOURA, D. H.. Educação Básica e Educação Profissional e Tecnológica: Dualidade

Histórica e Perspectivas de Integração. Revista Holos. Vol.2, Ano 23, p ( p.4-p.30.), 2007 Disponível em: 〈https://www2.ifrn.edu.br/ojs/index.php/HOLOS/article/view/II . Acesso em 23 outubro 202I.

ROBBINS, S. P. Comportamento organizacional. Rio de Janeiro: LTC, 1999.

ROBBINS, S. P.; DECENZO, D. A. Administração de recursos humanos. 6. ed. Rio de Janeiro: LTC, 200 .

SANTOS, C. B. Do Bacharel à docência: a percepção dos egressos do PEG/UFSM quanto a atuação profissional docente. 2017. 88f. Dissertação (Mestrado em Educação Profissional e Tecnológica). Universidade Federal de Santa Maria, Santa Maria, 2017.

SOUZA, M. G. S. Gestão de Pessoas na Educação: Organizando e conhecendo o perfil dos profissionais da educação do Amapá. CONSAD. Conselho Nacional de Secretários de Estado da Administração. 2017. Disponível em: http://consad.org.br/wp-content/uploads/2017/o5/Painel-o4_or.pdf. Acesso em: I3 junho 2020 . 
UNESP. Faculdade de Ciências Agronômicas. Biblioteca Prof. Paulo de Carvalho Mattos. Tipos de Revisão de Literatura. Botucatu,2015. Disponível em: $\langle$ https://www.fca.unesp.br/Home/Biblioteca/tipos-de-evisao-de-literatura〉. Acesso em 23 outubro 2021. 